\title{
ARQUITETURA E ESPAÇOS MUSEOLÓGICOS: EXPERIÊNCIAS A PARTIR DO PLANO DE REQUALIFICAÇÃO DO NÚCLEO ARQUITETÔNICO HISTÓRICO DE MANGUINHOS NA CIDADE DO RIO DE JANEIRO.
}

Pinheiro, Marcos José de A. ${ }^{1}$

Bevilaqua, Diego Vaz ${ }^{2}$

Sá, Bruno Teixeira de ${ }^{3}$

Zouain, Rosana S. ${ }^{4}$

\section{Introdução}

A Fundação Oswaldo Cruz (Fiocruz), com sua sede no Rio de Janeiro, Brasil, é vinculada ao Ministério da Saúde, e constitui-se em uma das mais conceituadas instituições de pesquisa, ensino e produção no campo da ciência e tecnologia em saúde pública da América Latina. A Fiocruz teve sua origem no antigo Instituto Soroterápico Federal no início do século XX com o objetivo de

\footnotetext{
${ }^{1}$ Fundação Oswaldo Cruz. Casa de Oswaldo Cruz marcos.pinheiro@fiocruz.br

${ }^{2}$ Fundação Oswaldo Cruz. Casa de Oswaldo Cruz diego.bevilaqua@fiocruz.br

${ }^{3}$ Fundação Oswaldo Cruz. Casa de Oswaldo Cruz bruno.sa@fiocruz.br

${ }^{4}$ Fundação Oswaldo Cruz. Casa de Oswaldo Cruz rosana.zouain@fiocruz.br
} 
70 Arquitetura e espaços... Pinheiro, M.; Bevilaqua, D.; Sá, B.; Zouain, S.

produzir soros e vacinas contra as doenças que assolavam a cidade do Rio de Janeiro, então capital do país. O Campus Fiocruz Manguinhos ocupa parte do terreno de 85 hectares, originário da antiga Fazenda de Manguinhos, no bairro do mesmo nome, situado na zona norte do Rio de Janeiro (OLIVEIRA, 2003).

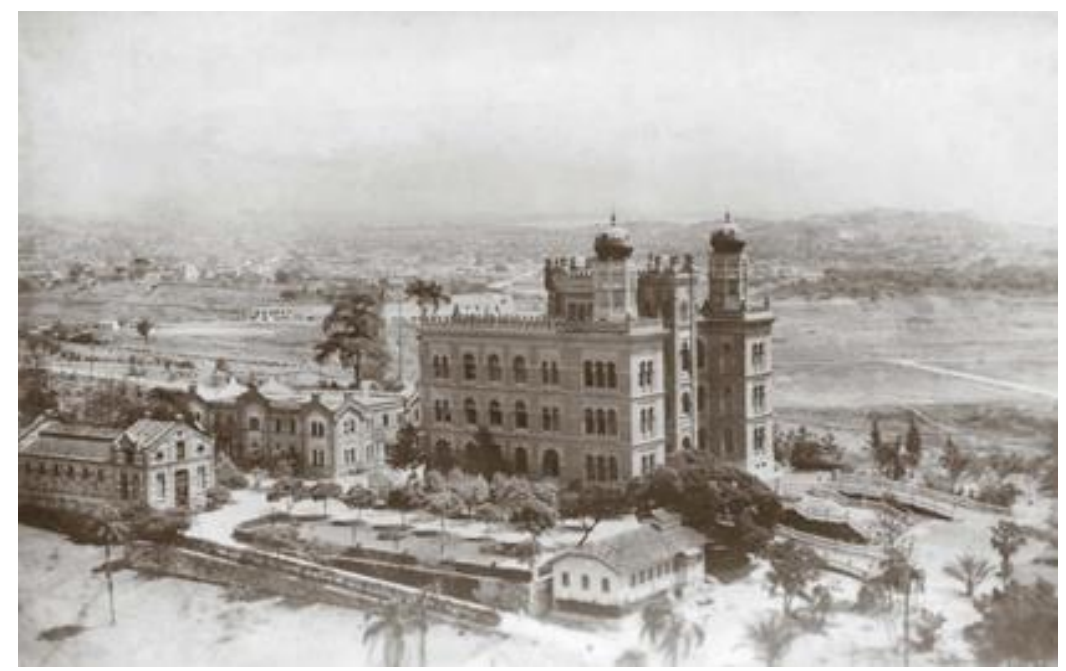

Figura 1 - Parte do Núcleo Arquitetônico Histórico de Manguinhos. Fonte: Acervo DAD/COC/Fiocruz.

Entre 1904 e 1922, sob a direção do médico sanitarista Oswaldo Cruz, foram erguidas as primeiras edificações projetadas pelo arquiteto português Luiz Moraes Jr., formando o que hoje se identifica como Núcleo Arquitetônico e Histórico de Manguinhos (NAHM). Esse conjunto é formado pelos edifícios erguidos em uma das colinas do terreno para substituir as antigas instalações da antiga fazenda, ocupadas pelos laboratórios do Instituto nos primeiros anos de sua fundação: o Pavilhão Mourisco (1905-1918), o Pavilhão do Relógio (1904-1905) e a Cavalariça (1904) - tombados pelo Instituto do Patrimônio Histórico e Artístico Nacional (IPHAN) em 1981 - o Pavilhão Figueiredo de Vasconcelos (1919-1921), a Casa de Chá (c. 1905) e seu anexo (c. 1920). 

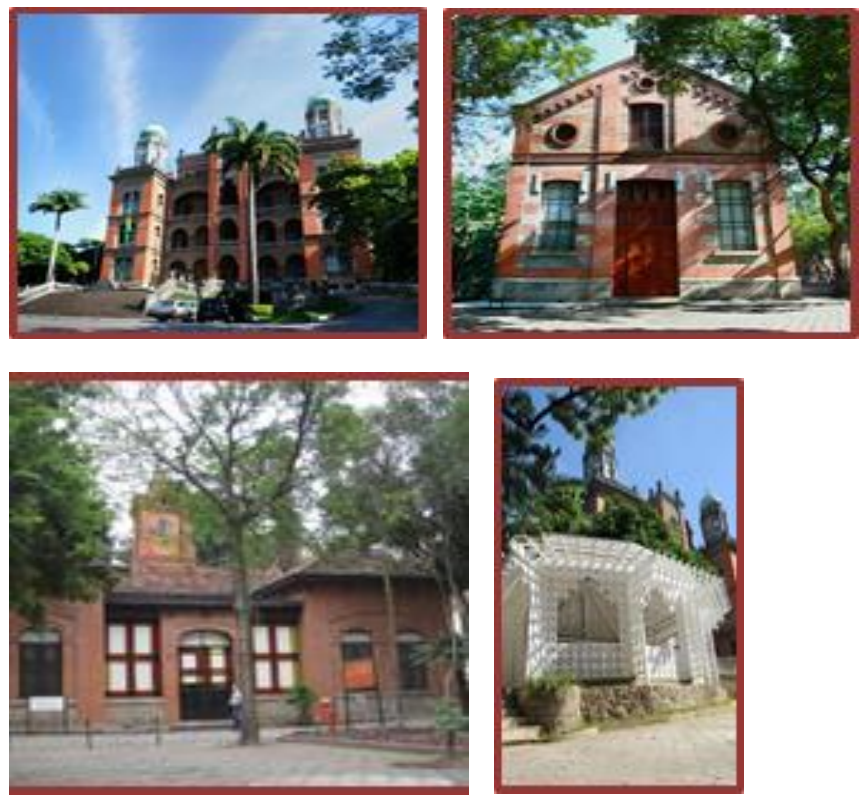

Figura 2 - Edifícios ecléticos do núcleo originário: Pavilhão Mourisco, Cavalariça, Pavilhão do Relógio, Casa de Chá. Fonte: Acervo DPH/COC

Afastados deste núcleo original, foram construídos no mesmo período o Hospital Evandro Chagas (1912-1918), o Pombal (1904) e o Pavilhão Vacínico, atual Casa Amarela (1922). Os jardins históricos integrados aos edifícios e a área verde envoltória complementam este conjunto. Cabe destacar ainda que o Campus Fiocruz Manguinhos está situado num sítio histórico que abriga vestígios arqueológicos pré-históricos e históricos ${ }^{5}$.

\footnotetext{
${ }^{5} \mathrm{O}$ sítio arqueológico de Manguinhos foi inscrito em 1966 na Ficha de Cadastro Nacional de Sítios (CNS) do Instituto do Patrimônio Histórico Nacional (IPHAN).
} 
72 Arquitetura e espaços... Pinheiro, M.; Bevilaqua, D.; Sá, B.; Zouain, S.

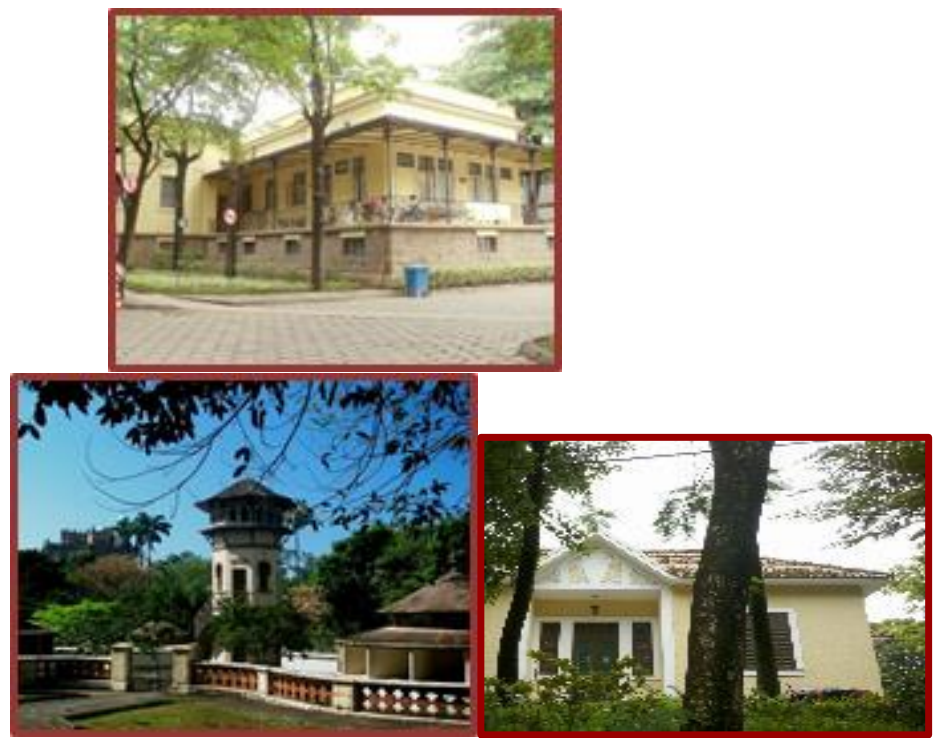

Figura 3 - Edifícios do Conjunto Eclético: Hospital Evandro Chagas, Pombal, Casa Amarela. Fonte: Acervo DPH/COC

Integram ainda o acervo arquitetônico da Fiocruz, o conjunto moderno, composto pelo antigo Restaurante Central, atual Pavilhão Augusto da Silva (1951), o Pavilhão de Cursos, hoje conhecido como Pavilhão Arthur Neiva (1947) - ambos tombados pelo Instituto Estadual de Patrimônio Cultural do Estado do Rio de Janeiro (INEPAC) - a portaria da Av. Brasil (1954) e o Laboratório da Febre Amarela (1956), atual Pavilhão Henrique Aragão. 

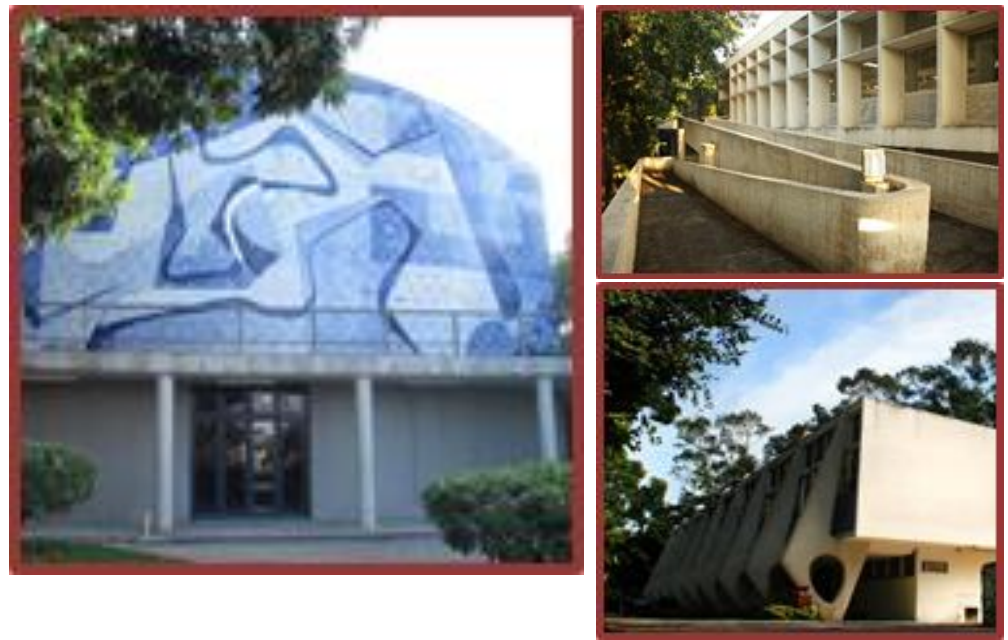

Figura 4 - Edifícios modernos: Pavilhão Carlos Augusto da Silva, Pavilhão Arthur Neiva e Pavilhão Henrique Aragão. Fonte: Acervo DPH/COC/Fiocruz.

Tendo em vista o patrimônio científico e cultural acumulado em seus mais de 100 anos de existência, a Fiocruz incorporou estruturas e processos para viabilizar a preservação desses acervos assim como sua disponibilização para a população brasileira. Um marco importante para a institucionalização destas práticas foi a criação, em meados da década de 1980, da Casa de Oswaldo Cruz $(\mathrm{COC})^{6}$, unidade técnico-científica dedicada à produzir e disseminar conhecimento histórico da saúde e das ciências biomédicas; preservar e valorizar a memória da Fiocruz e o patrimônio cultural das ciências e da saúde; educar em seus campos de atuação e divulgar ciência e tecnologia em saúde. A COC estrutura-se organizacionalmente em departamentos: Departamento de Pesquisa em História das Ciências e da Saúde (Depes); Departamento de Arquivo e Documentação (DAD); Departamento de Patrimônio Histórico (DPH) e o Museu da Vida.

${ }^{6}$ Ver em http://www.coc.fiocruz.br/ 
74 Arquitetura e espaços... Pinheiro, M.; Bevilaqua, D.; Sá, B.; Zouain, S.

A história da Fundação Oswaldo Cruz é, em grande parte, a história do desenvolvimento da ciência e da saúde pública no Brasil. Os edifícios projetados pelo arquiteto Luiz Moraes Jr são testemunhos de um dos períodos desta história, marcada pelos pensamentos e movimentos higienistas nas cidades e, por isto, constituem um dos mais importantes conjuntos relacionados ao patrimônio da saúde do nosso país. O acervo cultural e científico da Fiocruz, também composto por coleções biológicas, arquivísticas e bibliográficas são fontes de pesquisa para diversos estudos e objetos de interesse de preservação e divulgação.

Buscando o desenvolvimento de ações articuladas entre os diversos acervos da instituição, a Casa de Oswaldo Cruz elaborou o Plano de Requalificação do Núcleo Arquitetônico Histórico de Manguinhos que, entre seus princípios norteadores, propõe a ocupação dos edifícios históricos aliando sua preservação e valorização ao uso cotidiano. Aqui serão apresentados dois projetos museográficos distintos, o da Cavalariça e o do Pombal, elaborados no âmbito deste plano.

\section{Plano de Requalificação do Núcleo Arquitetônico Histórico de Manguinhos}

O Plano de Requalificação do Núcleo Arquitetônico Histórico de Manguinhos (NAHM) objetiva, por meio de intervenções e novos usos de suas áreas urbanas e edificações históricas, preservar e valorizar o patrimônio cultural situado no Campus Manguinhos da Fiocruz, ampliar o diálogo com o território em que se situa e com a cidade do Rio de Janeiro, atender às demandas institucionais, e gerar maior oferta de atividades socioculturais, de divulgação científica e de educação em ciências, tecnologia, saúde e de cultura aos trabalhadores da instituição e à sociedade.

\subsection{Contextualização}

A Fiocruz, uma instituição centenária reconhecida por adotar um posicionamento inovador e ativo em suas ações de pesquisa, 
educação, produção e prestação de serviços, também o foi em suas resoluções em preservar e tornar acessíveis os diferentes acervos culturais e científicos constituídos ao longo de sua história. Ainda em seus primórdios constituiu um museu dedicado às suas pesquisas na área biomédica, em especial à patologia, e a seguir, após a morte do cientista Oswaldo Cruz em 1917, um museu dedicado à sua memória.

A ação propositiva da Fiocruz em prol da preservação de seu patrimônio pode ser exemplificada, entre diversas iniciativas, pela criação da Casa de Oswaldo Cruz (COC). Esse posicionamento político da instituição de reconhecimento de sua memória e de seu patrimônio cultural como elementos estratégicos e estruturantes à sua cultura organizacional e ao cumprimento de sua missão, podem ser ainda evidenciados por um histórico de ações que visavam a valorização do patrimônio cultural constituído pela instituição e pela antecipação aos órgãos de tutela na esfera nacional, estadual ou municipal na proposição de medidas de salvaguarda. A partir da homologação pelo Instituto de Patrimônio Histórico e Artístico Nacional (IPHAN) do primeiro processo tombamento ${ }^{7}$, em 1980 , do Pavilhão Mourisco, Pavilhão do Relógio e Cavalariça, a Fiocruz entendeu que esse tombamento não era suficiente para a preservação do seu conjunto arquitetônico histórico e que seria necessária a tutela de uma área de entorno ao núcleo original. Diante dessa constatação, a própria Fiocruz solicitou ao IPHAN em 1985 a extensão do tombamento com a inclusão da área verde existente ao redor destas edificações e a inclusão de outras edificações do período eclético - o Pavilhão Figueiredo de Vasconcelos e o Pombal. Esse processo ${ }^{8}$ iniciado em 1986 ainda não foi concluído, mas a legislação vigente faz com que os objetos constantes no processo sejam tratados como efetivamente tombados com base no entendimento jurídico e administrativo de se adotar medida cautelar uma vez iniciado o processo. A poligonal

\footnotetext{
${ }^{7}$ Processo de Tombamento $\mathrm{n}^{\mathrm{o}}$ 1.037-T/80, IPHAN.

${ }^{8}$ Processo de Tombamento $\mathrm{n}^{\mathrm{o}} 1.037-\mathrm{T} / 80$, IPHAN.
} 
76 Arquitetura e espaços... Pinheiro, M.; Bevilaqua, D.; Sá, B.; Zouain, S.

correspondente à essa área verde foi referência para o Plano Diretor do Campus de 1988, e planos subsequentes.

Em 2001 foi publicado o tombamento de duas edificações modernistas pelo órgão de tutela do Estado do Rio de Janeiro, o Instituto Estadual de Patrimônio Cultural (INEPAC). Essas edificações são representantes de um segundo período de expansão no campus que ocorreu entre os anos 1940 e 1974 (OLIVEIRA, COSTA e PESSOA, 2003), com uma arquitetura de expressão moderna, e o tombamento decorreu de solicitação por parte da Fiocruz, motivada pela defesa da preservação e valorização da arquitetura moderna brasileira.

Já na segunda década do século XXI, a instituição solicitou ao INEPAC o tombamento de mais duas edificações modernistas situadas nesse campus, processo que ainda está em análise.

Ainda na linha propositiva, em 2013 foi concluído o Plano de Ocupação da Área de Preservação do Campus Fiocruz Manguinhos (POAP), elaborado pela COC/Fiocruz com consultoria do Instituto Brasileiro de Administração Municipal (IBAM) e aprovado pelo Conselho Deliberativo da Fiocruz em 19 de dezembro de 2013. O POAP é um instrumento institucional de planejamento e gestão do acervo arquitetônico, urbano e paisagístico do Campus Fiocruz Manguinhos. Foi construído sob a liderança do Departamento de Patrimônio Histórico (DPH)/ COC, que coordenou um grupo de trabalho constituído por profissionais da COC, de representantes das diferentes unidades que ocupam a área objeto ou têm por ela responsabilidades técnico-administrativas, além de representações dos órgãos estadual e federal de proteção do patrimônio cultural. Garantir a integridade, visibilidade e legibilidade dos bens de interesse para preservação da área de preservação é um de seus principais objetivos, assim como o de consolidar a vocação do campus como "Campus-Parque", entendido "como um ambiente saudável, seguro, confortável e culturalmente enriquecedor, para seus funcionários e visitantes". (CASA DE OSWALDO CRUZ, INSTITUTO BRASILEIRO DE ADMINISTRAÇÃO MUNICIPAL, 2011, pp. 18-19) 
Como metodologia, o POAP dividiu a área de preservação do campus em quatro áreas de estudo, e para cada uma delas desenvolveu propostas considerando dois cenários. Para a Área de Estudo 1, no qual se insere o Núcleo Arquitetônico Histórico de Manguinhos (NAHM), o cenário mais conservador previa "a manutenção dos usos atuais nos bens de interesse para preservação e nos demais edifícios da Praça Pasteur", enquanto o segundo cenário considerava a transferência de parte do uso administrativo para um novo polo, possibilitando a disponibilização destes espaços para a fruição do público externo. Vale ressaltar que este cenário já considerava a desocupação do Pavilhão do Relógio, um dos edifícios históricos do núcleo que abrigava a direção da COC, por conta da construção do Centro de Documentação em História da Saúde (CDHS), concluído em 2017.

Nesse contexto de mudanças surge a proposta de elaboração do Plano de Requalificação do Núcleo Arquitetônico Histórico de Manguinhos, com o objetivo de propor novos usos e ocupações para esses espaços que, além de valorizá-los e garantir sua integridade, ampliassem seu acesso à sociedade (PINHEIRO, MARQUES, e COELHO, 2017). Esse cenário também trouxe desafios, que se não enfrentados poderiam comprometer a conservação e a valorização do NAHM, visto que a ausência de projetos colocaria as edificações históricas à mercê do improviso e de ocupações decorrentes da falta de planejamento.

\subsection{Metodologia de desenvolvimento participativo}

A Fiocruz adota desde os anos 1980 um modelo singular de governança no âmbito da administração pública no Brasil, com base numa gestão participativa na qual práticas democráticas estão incorporadas aos processos de tomada de decisão corporativa e na eleição de seus dirigentes. Esse modelo pressupõe que as decisões, diretrizes e planejamentos resultem de deliberações colegiadas e para tal que haja uma estrutura de governança com distintas instâncias organizacionais em diversos níveis hierárquicos, sendo algumas de caráter consultivo e outras deliberativas. Essa cultura 
78 Arquitetura e espaços... Pinheiro, M.; Bevilaqua, D.; Sá, B.; Zouain, S.

organizacional de envolver amplamente diferentes atores e instâncias institucionais, faz com que iniciativas ou projetos que pretendam maior legitimidade na instituição adotem em sua metodologia de desenvolvimento a constituição de grupos de trabalho com ampla representação, que sejam submetidos à avaliação de diferentes instâncias consultivas e tenham sua aprovação em algum nível de colegiado com caráter deliberativo de acordo com sua abrangência e relevância.

Um fator considerado também no ambiente institucional é o mérito de quem propõe algo e, no caso da formulação e liderança de um projeto como o Plano de Requalificação, a Casa de Oswaldo Cruz é a unidade a qual a instituição espera que se apresente como responsável e proponente. Ainda em 2011 foi constituído no âmbito da unidade um primeiro grupo de trabalho formado por profissionais das áreas do patrimônio cultural, da divulgação científica, da pesquisa e da educação, tendo como primeira missão discutir e redigir um documento de referência para definição de valores, objetivos e orientação para todos os projetos e ações necessários à construção e implementação do referido plano. Ainda nessa fase inicial, foram convidados especialistas externos para apresentar suas sugestões e experiências profissionais nos campos da preservação do patrimônio arquitetônico, museologia, museografia e comunicação em museus. Esses profissionais deveriam possuir alguns dos seguintes atributos: ter histórico de relação ou conhecimento sobre a instituição; ser reconhecido em sua área de atuação; representar segmentos distintos da sociedade.

Em 2013, foi revista e ampliada a composição do grupo de trabalho, instituído por meio de portaria da direção da COC. Internamente à unidade, mecanismos para ampliar a visibilidade do projeto foram criados, tais como o uso do portal web da $\mathrm{COC}$, e as etapas de desenvolvimento do projeto foram paulatinamente apresentadas e debatidas com os principais departamentos envolvidos assim como no âmbito do Conselho Deliberativo da unidade e nas Câmaras Técnicas, instâncias consultivas, que tratam do patrimônio cultural, da educação e da divulgação científica. No 
âmbito da Fiocruz, o Plano foi apresentado, debatido e aprovado com as direções das unidades que ocupam o NAHM, com a presidência e suas vice-presidências. Ressalta-se que o trabalho foi desenvolvido muito próximo à Coordenação-Geral de Infraestrutura dos Campi (Cogic), e articulado ao desenvolvimento do plano diretor do Campus Manguinhos.

Posteriormente, em 2014, quando já se tinha uma proposta estruturada do Plano de Requalificação, foi feita uma enquete por meio da web, dirigida aos trabalhadores e estudantes da instituição, para identificar seus principais interesses nas atividades propostas pelo Plano, inclusive em relação aos temas a serem abordados nas futuras exposições. A pesquisa foi respondida por 1.240 pessoas, dos quais $98 \%$ confirmaram o interesse em trazer a família e amigos para visitar o campus. Foi possível identificar que os temas a princípio previstos ao projeto estavam de acordo com aqueles preferidos para as futuras exposições.

As atribuições do grupo de trabalho envolveram a definição dos usos e ocupações, dos programas de necessidades, do modelo de gestão e dos públicos alvo interno e externo. O desenvolvimento do plano tomou como base em seu macroplanejamento metodologias de gestão de projetos, de modo a se considerar diferentes cenários e se estabelecer para cada um, os riscos associados e as alternativas possíveis. Considerou-se como princípios a serem perseguidos a acessibilidade plena e a sustentabilidade do projeto, em suas diversas fases. Para o desenvolvimento de distintas dimensões do projeto, viu-se a necessidade de se criar diferentes programas capazes de dar maior autonomia e agilidade aos processos necessários para sua concretização. Criou-se um Programa de Comunicação, responsável pela escuta tanto da comunidade interna como dos visitantes e de novos públicos potenciais, além de produzir matérias na mídia e materiais de comunicação do projeto em mais de um idioma, necessários à captação de recursos e à efetivação de cooperações com outras instituições nacionais e internacionais. Esse programa 
80 Arquitetura e espaços... Pinheiro, M.; Bevilaqua, D.; Sá, B.; Zouain, S.

envolveu ainda uma consultoria dedicada a estudar o melhor nome, posicionamento, plataforma de marca e identidade ao projeto.

Foram também criados os Programas de Captação de Recursos, de Cooperação e o de Gestão Institucional. O de captação de recursos considera que são necessários os recursos da instituição para o desenvolvimento dos projetos, para parte das obras de intervenção, e que se deve contar com orçamento ordinário para sua conservação, mas que o Plano de Requalificação estrategicamente necessita de expressivos recursos externos para sua viabilização. Para isso, o plano foi dividido em diferentes etapas de execução, envolvendo a submissão individual de cada edificação ao Programa Nacional de Apoio à Cultura, do Ministério da Cultura do Brasil e a outras leis de incentivo fiscal, associado a um conjunto de patrocinadores que manifestaram interesse. Prevê também a sua submissão a editais e a fundos internacionais.

O Programa de Cooperação visa dar visibilidade nacional e internacional ao plano, capacitar nossos profissionais, e contribuir para que possamos construir no campus uma exposição de ciência e tecnologia de grande importância na América Latina, desenvolvida em espaços centenários dentro de um campus em pleno exercício de suas atividades científicas, além de oferecer à cidade do Rio de Janeiro mais uma atração histórica, turística e cultural numa área reconhecida por sua baixa oferta de museus e de equipamentos culturais.

Por fim, o Programa de Gestão Institucional dos espaços visa definir responsabilidades, propor estruturas compartilhadas de governança, dado que além da COC como unidade formuladora do projeto e responsável pelas ações de preservação dos acervos e de divulgação científica, há outras unidades da instituição, além de sua presidência, que continuarão a ocupar o NAHM e suas áreas de entorno.

\subsection{Princípios, diretrizes e sustentabilidade.}

O Plano de Requalificação abarca as edificações que compõem o núcleo originário da instituição, formada pelas 
edificações construídas nas primeiras décadas do século $X X$, à exceção do Hospital Evandro Chagas e da Vila Residencial, que são o Pavilhão Mourisco, o Pavilhão do Relógio, o Pavilhão Figueiredo de Vasconcelos, e a Casa de Chá. Inclui ainda a Praça Pasteur, o Caminho Oswaldo Cruz e o Pavilhão Henrique Aragão, de modo a conformar uma área contínua de intervenção. Após definição do espaço de atuação, o Grupo de Trabalho se encarregou de produzir um documento de referência, e para tal houve a necessidade de escuta e construção de consensos na instituição sobre os princípios e diretrizes que fossem capazes de traduzir os valores e a identidade da Fiocruz e de intensificar a relação da instituição com o território onde se situa o Campus Manguinhos e com a cidade do Rio de Janeiro.

Como princípio central para desenvolvimento deste plano, há de se considerar que as intervenções em sítios e conjuntos históricos devem ser pautadas por quatro esferas que traduzem a ação humana num dado lugar ao longo do tempo: a esfera cultural, que abarca os valores artísticos e históricos; a esfera social, que abarca os aspectos simbólicos e da memória; a esfera ética, que compreende o direito de transmissão e fruição entre gerações dos testemunhos, da vida cotidiana e das memórias individuais e coletivas; e, por último, a esfera científica, por se tratar de um lugar notável de geração de conhecimento que constituiu acervos culturais e científicos com enorme potencial para fomentar novas pesquisas em diferentes áreas da ciência (FUNDAÇÃO OSWALDO CRUZ. CASA DE OSWALDO CRUZ, 2014, p.10). 
82 Arquitetura e espaços... Pinheiro, M.; Bevilaqua, D.; Sá, B.; Zouain, S.

Segundo o Documento de Referência, a requalificação do NAHM incorpora em sua totalidade o POAP e é parte integrante do plano diretor que orienta as ocupações e intervenções em todo o Campus Manguinhos. O Documento estabelece que além do princípio central e dos valores supracitados, o Plano de Requalificação deve se orientar pelo fortalecimento da relação entre a Fiocruz, como uma instituição de ciência e tecnologia, e a sociedade no campo da saúde; por uma requalificação sustentável; por preservar a singularidade e a identidade da instituição e por valorizar o seu cotidiano e o trabalho que realiza.

Para uma requalificação sustentável, tomou-se como base um conceito mais ampliado à sustentabilidade na reabilitação de áreas históricas ${ }^{9}$, que considera que um projeto dessa natureza não deve se ater à procura pela eficiência no uso de recursos naturais e pela diminuição do impacto ambiental, que se configuram como condições necessárias, mas insuficientes. Há, portanto, de se considerar conjuntamente no caso desse plano de requalificação, a melhoria da qualidade de trabalho e de vida dos trabalhadores e usuários do NAHM e do Campus Manguinhos; a valorização do patrimônio cultural e natural do campus; a melhoria da coesão social com o fomento da cidadania e da valorização das diversidades; e na promoção da vitalidade socioeconômica do território.

O Plano de Requalificação propõe a ocupação do espaço que é objeto de intervenção subdivido em cinco macro-áreas, como referências de uso e ocupação para o desenvolvimento dos programas de necessidades: a) áreas de representação políticoinstitucional; b) áreas de manutenção de atividades atuais; $c$ ) áreas de infraestruturas para eventos técnico-científicos e culturais; d)

\footnotetext{
${ }^{9} \mathrm{O}$ trabalho tomou como referência os estudos produzidos pela Rehabimed. A Rehabimed é uma rede interdisciplinar da região do Mediterrâneo, orientada à reabilitação sustentável, à restauração do patrimônio e à regeneração urbana, com vistas à revitalização socioeconômica dos centros históricos no Mediterrâneo, e dessas experiências subsidiar ações em outras regiões. Ver em http://www.rehabimed.net/es/
} 
áreas de ampliação e qualificação de espaços de convívio e espaços públicos; e) áreas de educação e divulgação científica (Figura 5).
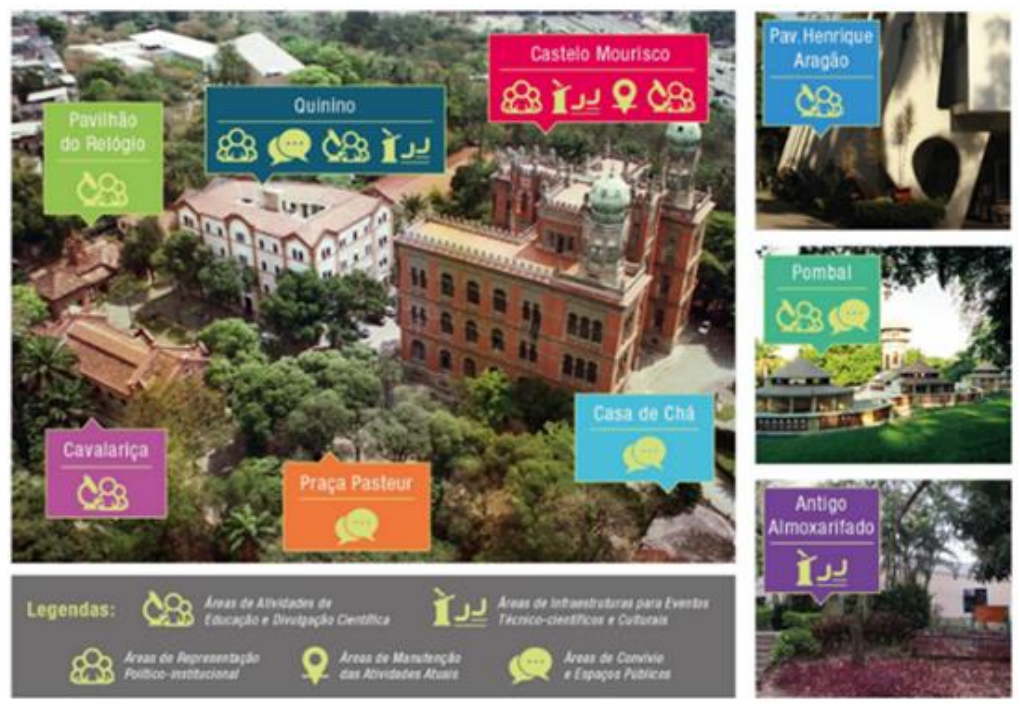

Figura 5: Proposta de ocupação dos espaços pelo plano de requalificação. Fonte: Documento de Referência. Fiocruz, Casa de Oswaldo Cruz, 2014

As áreas de tipo (a) e (b) estão alinhadas aos princípios de uma ocupação que preserva a identidade da instituição, incluindo seu cotidiano e o trabalho em curso, visam a permanência de usos que não comprometam a integridade do núcleo, evitando a invenção de novos significados que impeçam a leitura ou a percepção da cultura e do dia-a-dia institucional.

As áreas de tipo (c) visam valorizar e compartilhar a produção do conhecimento nos campos de atuação da instituição, qualificando-as como de potenciais espaços de convenções científicas e culturais. Propõem-se a suprir uma demanda institucional por mais espaços e infraestruturas para eventos científicos, e permitirão uma ocupação com fluxos de maior 
84 Arquitetura e espaços... Pinheiro, M.; Bevilaqua, D.; Sá, B.; Zouain, S.

permanência e a possibilidade de maior atração e de melhor convívio e diálogo entre o corpo profissional e o público visitante.

As áreas de tipo (d) visam atender à proposição de transformação em um "campus parque" e têm como base o princípio da requalificação sustentável, com a oferta de lugares de diálogo e a ampliação de fruição do NAHM por parte da comunidade da instituição e de seus visitantes. Atende uma demanda contemporânea nos campi universitários e por instituições de pesquisa e de ensino por áreas de contemplação, de lazer, e de reuniões informais.

As áreas de tipo (e) tomam como seu cerne intensificar a relação da instituição com a cidade e o território de Manguinhos e Maré, tomando como base a ampliação das ações museológicas e considerando em sua ocupação as vocações institucionais de pesquisa, educação, divulgação científica, preservação patrimonial e ambiental e de atividades socioculturais voltadas à população. A relevância desse uso e ocupação revela-se quando se observa que o campus está localizado numa região de alto grau de vulnerabilidade socioeconômica, circundado por bairros situados entre os de mais baixos Índices de Desenvolvimento Humano (IDH) no município do Rio de Janeiro. Ratifica-se assim o objetivo de ampliar a oferta de espaços e de atividades educativas, culturais e de divulgação científica à sociedade. Para o desenvolvimento dessas áreas são propostos cinco eixos temáticos que possibilitam 0 seu desdobramento em temas que deem conta de diversos contextos, abordagens, visões e temporalidades, e que serão melhor detalhados à frente.

Uma premissa para o desenvolvimento do Plano de Requalificação é a sua sustentabilidade como projeto. Como já descrito anteriormente, um fator favorável é o histórico da instituição em seu posicionamento ativo e propositivo na preservação de seus bens culturais e na formação de equipes com competência para conservar seus acervos culturais e desenvolver projetos dessa natureza e dimensão. Trata-se de ação reconhecida pela obtenção de diversas premiações nacionais e por ter tido três 
de seus fundos arquivísticos e um manuscrito reconhecidos pelo Programa Memória do Mundo da Unesco. Para além desse componente da cultura institucional, fez-se necessário atuar em diferentes frentes estratégicas, com destaque a duas. Uma centrada na produção da narrativa central do projeto, nos seus princípios e valores, e em sua metodologia de desenvolvimento. E outra voltada ao conhecimento e comprometimento político da alta cúpula da Fiocruz em sua realização, envolvendo Presidência e VicePresidências, bem como dos diretores de unidades parceiras, o que vem se renovando no tempo a cada mudança de gestão. Ainda no campo da aceitação social da proposta, atua-se por meio do Programa de Comunicação, um dos programas criados para a implantação do projeto, a partir de diferentes estratégias e mídias na divulgação e na formulação de canais de diálogo com os distintos atores e públicos. Um dos eixos estruturados para a sustentabilidade do projeto e que tem obtidos êxitos é o Programa de Cooperação, essencial para a visibilidade do projeto e para o compartilhamento de experiências e de saberes. O programa já concretizou cooperações técnicas com instituições tais como o Museum National d'Histoire Naturelle e o Universcience ${ }^{10}$, da França; e o Science Museum Group ${ }^{11}$, do Reino Unido, motivadas pelo interesse no compartilhamento de experiências nos campos da preservação patrimonial e da divulgação científica e revelam credibilidade no que se propõe a construir. Soma-se a esse o Programa de Captação de Recursos, descrito anteriormente como relevante na obtenção de receita suplementar ao previsto no orçamento ordinário. A captação de recursos de fontes externas configura-se como estratégico elemento de afirmação interna na instituição, de modo a viabilizar o Plano politicamente, minimizando a percepção pelos demais entes institucionais de ser um elemento

\footnotetext{
${ }^{10} \mathrm{O}$ grupo, com sede em Paris, compreende dois museus de ciências, o Palais de La Découvert e o Cité des Sciences et de L'Industrie.

${ }^{11} \mathrm{O}$ grupo, com sede em Londres, compreende diferentes museus de ciência no Reino Unido, como o National Science Media Museum, o Science Museum, o National Railway Museum, o Museum of Science and Industry e o Locomotion.
} 
86 Arquitetura e espaços... Pinheiro, M.; Bevilaqua, D.; Sá, B.; Zouain, S.

de disputa por recursos internos com as áreas de pesquisa, educação, serviço e produção da Fiocruz.

Somando-se esses componentes à adoção da requalificação sustentável como um dos princípios norteadores ao projeto, podese afirmar a sustentabilidade do Plano de Requalificação do NAHM com base no seguinte:

- Tradição da instituição na preservação de seu patrimônio cultural;

- Reconhecimento e atração de competências essenciais;

- Aceitação social da proposta;

- Adoção de padrões sustentáveis nos projetos arquitetônicos e urbanísticos;

- Parcerias público-privadas;

- Compromisso assumido pelos gestores da instituição

Para viabilizar a implantação do Plano de Requalificação foi previsto um cronograma subdividido em quatro fases com intervalos temporais, sendo em cada uma das fases considerado um grupo de edificações, que serão objeto das intervenções necessárias para sua disponibilização à sociedade. Essa subdivisão foi necessária pela melhor eficiência na administração dos recursos técnicos e orçamentários, e devido ao fluxo de desocupação das edificações. Esse fluxo ocorre por algumas edificações estarem ainda ocupadas e dependentes da construção de outro prédio para transferência de seus atuais usuários. As quatros fases têm sua previsão de término em 2026, mas com entregas intercaladas e sucessivas. 


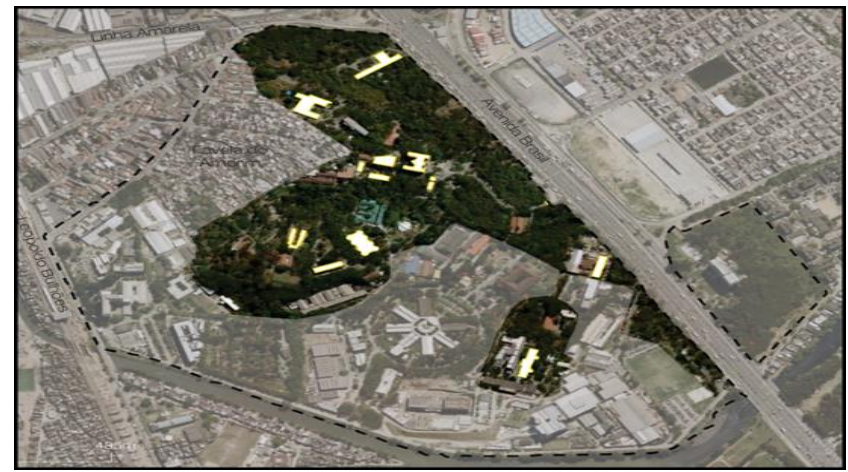

Figura 6 - Campus Manguinhos e Área de Preservação. Fonte: $\mathrm{DPH} / \mathrm{COC}$, sobre base GoogleMaps

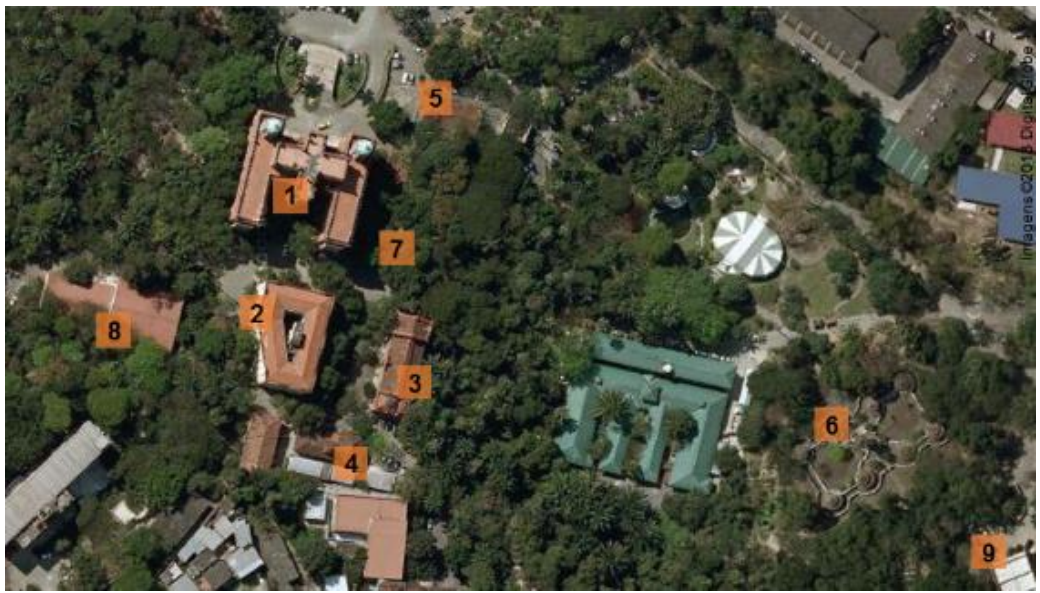

Figura 7 - Edifícios contemplados no Plano de qualificação do NAHM: Pavilhão Mourisco (1); Quinino (2); Cavalariça (3); Pavilhão do Relógio (4); Casa de Chá e Anexo (5); Pombal (6); Praça Pasteur (7); Antigo Almoxarifado (8); Pavilhão Henrique Aragão (9). Fonte: DPH/COC, sobre base GoogleMaps.

\subsection{Eixos temáticos}

A partir do grupo de trabalho interdisciplinar constituído para discussão do plano de requalificação do NAHM, definiu-se que as exposições que ocupariam os espaços históricos que estavam sendo discutidos teriam uma organização temática (DEAN, 2003), cujos temas estariam em sintonia com os grandes eixos de planejamento 
88 Arquitetura e espaços... Pinheiro, M.; Bevilaqua, D.; Sá, B.; Zouain, S.

estratégico da Fiocruz (FIOCRUZ, 2010) e da Casa de Oswaldo Cruz (FIOCRUZ, 2015). Conforme a análise feita pelo grupo de trabalho feito a partir desses documentos, os eixos temáticos a serem abordados foram definidos como: Saúde Pública no Brasil; Ciência e Tecnologia em Saúde; Saúde, Ambiente e Sustentabilidade; Acervos Culturais da Saúde; e Fiocruz e as Cidades.

Para desenvolver cada um dos eixos, cinco novos grupos com especialistas da Fiocruz e de instituições parceiras foram convidados para escrever documentos de referência delimitando cada tema, documentos que foram todos validados pelo grupo de trabalho do Plano. É importante esclarecer que os eixos temas definidos para o Plano não são cristalizados no objeto de uma única exposição, mas atuam de forma transversal em várias das exposições que estão planejadas, sendo cada exposição um produto da intersecção de dois ou mais temas pré-definidos. Esses recortes transversais para cada uma das exposições vêm de uma análise do próprio grupo de trabalho que levou em conta a arquitetura de cada edificação, a sua história de uso e sua localização geográfica dentro do Campus.

\section{- Saúde Pública no Brasil}

Esse eixo trata da história da saúde no Brasil, com foco no período que se inicia durante a primeira república, quando foi fundado o Instituto Soroterápico Federal (nome da Fundação Oswaldo Cruz na época), e vai até a história do tempo presente. Com destaque teremos as expedições científicas da primeira metade do séc. XX, o movimento da reforma sanitária e a criação e implementação do Sistema Único de Saúde no Brasil

\section{- $\quad$ Ciência e Tecnologia em Saúde}

Esse eixo trata da pesquisa contemporânea, inovação científica e desenvolvimento tecnológico no campo da saúde, que se expressa tanto na produção de vacinas quanto no campo das ciências biomédicas, especialmente da medicina tropical. Os tópicos aqui tratados devem relacionar a produção em ciência e tecnologia 
com as demandas sociais e diretrizes políticas nacionais e internacionais em saúde.

\section{- Saúde, Ambiente e Sustentabilidade}

Esse eixo aborda as relações entre saúde e ambiente com foco na sustentabilidade do desenvolvimento humano. Esse tema está relacionado com os impactos das atividades humanas sobre o ambiente e seus impactos na saúde, como a contaminação crescente do solo e da água e as mudanças climáticas, assim como o impacto de ações como a opções ligadas à matriz energética e disposição inadequada de resíduos. Também será levado em conta os efeitos de políticas públicas relacionadas às condições de trabalho e moradia, uso de agrotóxicos e poluição atmosférico. Outra perspectiva a ser considerada é o uso sustentável de recursos naturais como fonte de saúde e o aproveitamento da biodiversidade na pesquisa científica em saúde.

\section{- Acervos Culturais da Saúde}

Esse eixo trata da riqueza e diversidade dos acervos culturais e científicos sob a tutela da Fiocruz. A partir dos seus acervos arqueológicos, arquitetônicos, arquivísticos, bibliográficos, biológicos e museológicos é possível destacar seus valores históricos e científicos, como fontes para produção do conhecimento científico e fazer a ponte entre a história do desenvolvimento científico e a produção contemporânea de saberes.

\section{- $\quad$ Fiocruz e as Cidades}

Esse eixo trata da relação entre os campi da Fiocruz e os territórios em que estão relacionados. Muitos dos campi onde estão as instalações da instituição guardam uma conexão profunda com seu local e suas comunidades, dentro de uma relação entre cidade, território e cultura. Em particular, no caso do campus de Manguinhos, foco principal do Plano de Requalificação, foi uma região que passou por ocupações Tupinambás, com o desenvolvimento da cidade do Rio de Janeiro passou a ser região de 
90 Arquitetura e espaços... Pinheiro, M.; Bevilaqua, D.; Sá, B.; Zouain, S.

fazendas até no final do século XIX abrigar um grande projeto de forno de incineração urbana de lixo e paralelamente, já no século XX as primeiras instalações da instituição que viria a constituir a Fiocruz. Ao longo do século XX a região passou por uma expansão da Fiocruz e seus vários conjuntos arquitetônicos, além de uma expansão industrial no entorno, que vem a entrar em decadência no final do século e fica marcando então pela ocupação desordenada do território. Nesses diferentes cenários foram sendo construídas as relações entre a instituição e a cidade

\section{Preservação do patrimônio arquitetônico e uso museológico: os projetos para a Cavalariça e para o Pombal}

A Cavalariça e o Pombal, edificações que integram o Plano de Requalificação do NAHM, pertencem ao primeiro ciclo de implantação do campus, e à primeira fase de implementação do projeto, juntamente ao Caminho de Oswaldo Cruz, já concluído. No âmbito do Plano de Requalificação, estão sendo destinadas à ampliação de espaços expositivos de divulgação científica na Fiocruz, por meio do Museu da Vida, setor responsável por ações desse tipo na instituição.

As propostas de ocupação destas edificações foram determinadas em função de suas características arquitetônicas, com resultados bastante diferentes quanto aos meios utilizados na comunicação com o público, e que se mostram como interessantes objetos de estudo sobre as possibilidades e desafios inscritos em projeto de intervenção em núcleos históricos constituídos por construções singulares entre si e na proposição de sua ocupação por exposições museológicas.

$\mathrm{Na}$ Cavalariça, edifício construído para a produção de soro contra a peste bubônica com características da arquitetura industrial inglesa do século XIX, optou-se pela utilização tanto de tecnologias avançadas quanto de outras soluções interativas, como dioramas e exposição de acervos. A variedade de soluções 
expositivas visa criar uma leitura diversa com foco em diferentes públicos e no tema da saúde em suas diferentes escalas de complexidade, de forma harmônica às características arquitetônicas do edifício.

Já o Pombal, antigo biotério ao ar livre para pequenos animais, apresenta características originais funcionalistas e com pouca ornamentação, trazendo como desafio a proposta de soluções que evidenciem seu aspecto singelo. Diante disto, foram propostas pequenas soluções expositivas integradas às áreas edificadas e ao paisagismo do entorno da edificação, com o objetivo de oferecer um lugar de fruição e lazer para exploração livre do público bem como integrá-lo às trilhas ecológicas e históricas já realizadas pelo Museu da Vida. A seguir desenvolvemos mais detalhadamente os projetos de intervenção em cada uma das duas edificações.

\subsection{Cavalariça}

A Cavalariça, construída entre 1904 e 1905, foi utilizada para abrigar os animais utilizados no processo de produção do soro cuja etapa final era realizada no Pavilhão da Peste (atual Pavilhão do Relógio). No edifício, nota-se a influência da arquitetura inglesa, sobretudo na ornamentação das fachadas, compostas por tijolos e blocos granito aparentes. O estilo inglês está presente ainda no interior do edifício, nos elementos metálicos das baias, escadas internas e estrutura da cobertura. 
92 Arquitetura e espaços... Pinheiro, M.; Bevilaqua, D.; Sá, B.; Zouain, S.

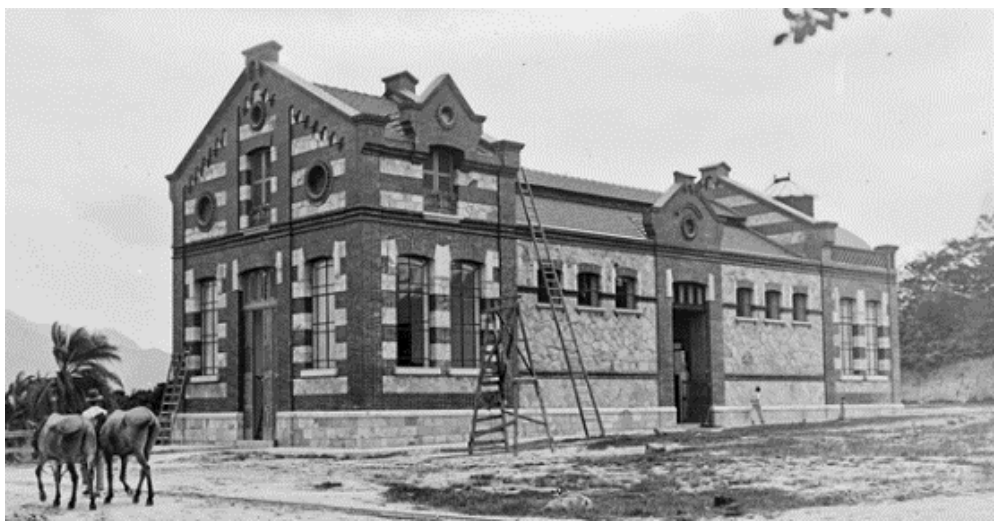

Figura 8 - Cavalariça após a construção. Fonte: Acervo DAD/COC/Fiocruz

O edifício se configura como um galpão de planta retangular onde um grande salão central separa duas alas nas quais se situavam atividades relacionadas ao tratamento dos cavalos: de um lado, uma sala para intervenções cirúrgicas e na ala oposta, um local onde eram realizadas as sangrias. As baias para os cavalos foram dispostas no salão central, separadas por grades de ferro com lambris de madeira. A distribuição das forragens utilizadas para alimentação dos animais era feita através de corredores elevados localizados entre as baias e as paredes externas, permitindo livre movimentação ao cavalariço. Obedecendo aos critérios de higiene adotados nos laboratórios no início do século $X X$, as paredes internas foram revestidas a meia altura em azulejos brancos com peças arredondadas para o arremate das quinas. 


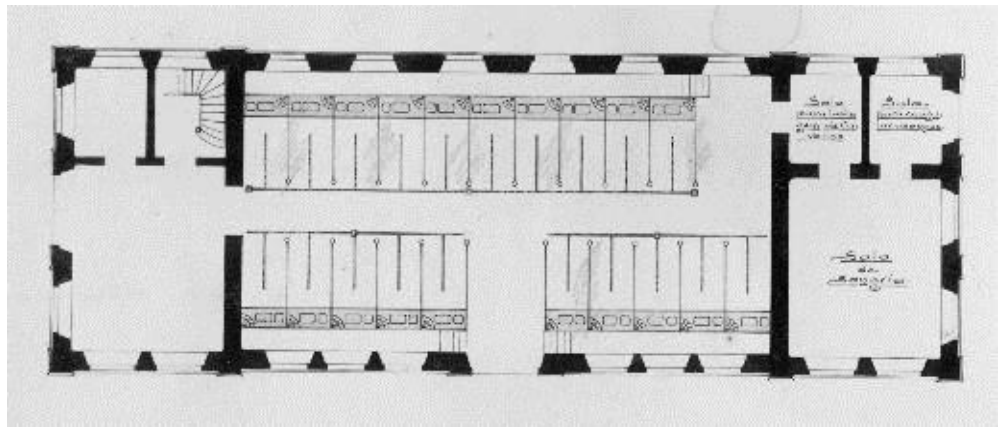

Figura 9 - Planta original da Cavalariça (1905) - Fonte: acervo DAD/COC

Como nos outros edifícios projetados pelo arquiteto português, foram adotadas tecnologias consideradas bastante avançadas para a época como um sistema automatizado denominado flushing tank, que descarregava a água automaticamente de 4 em 4 horas para a assepsia das baias. Além disto, houve preocupação com o reaproveitamento das águas servidas para irrigação do terreno onde eram cultivadas as forragens, a utilização do estrume para adubo e dos gases provenientes da fermentação das fezes dos animais para a iluminação.

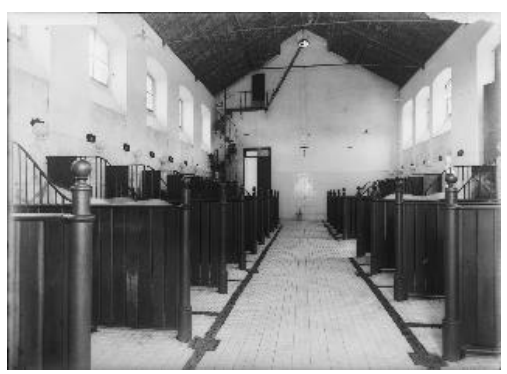

Figura 10 - Interior da Cavalariça

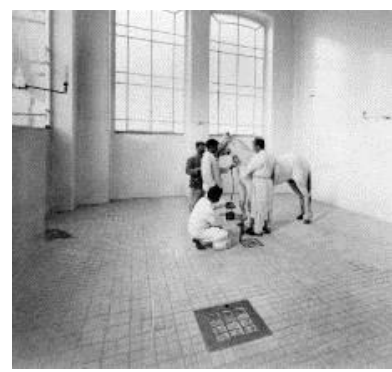

Figura 11- Sala da Sangria 
94 Arquitetura e espaços... Pinheiro, M.; Bevilaqua, D.; Sá, B.; Zouain, S.

Desde o final dos anos 70, a edificação vem sendo sistematicamente utilizada como espaço de exposições dentro da Fiocruz (SOARES E NOGUEIRA, 2017). Em meados da década de 1990, com o surgimento do projeto do Museu da Vida, o edifício passou por uma obra de restauração seguida de intervenções para adequação do espaço ao uso expositivo. Inaugurada em 1999, a exposição de longa duração, denominada "Biodescoberta", foi concebida para divulgar conceitos básicos de biodiversidade (GABRIEL E TEIXEIRA,1999, MARANDINO, 2016). A expografia montada buscava uma ambientação para a "imersão" do visitante e contava com diversos equipamentos e dispositivos. Foram instalados módulos temáticos que encobriram parte de seus bens integrados e paramentos com painéis de madeira e pisos elevados para garantir a acessibilidade física da edificação. Motivada inicialmente por problemas de infiltrações no edifício, em 2014 foram iniciadas as obras de restauração e, somente após a desmontagem da exposição, foi possível observar o estado de conservação dos materiais e elementos integrados que estiveram escondidos ao longo desses anos. Foi identificado o surgimento de patologias, tais como oxidações nos elementos em ferro fundido devido à umidade e colonização biológica nos azulejos e alvenarias (SÁ e MARTIRE, 2016), que poderiam ter sido tratadas com ações simples de conservação que teriam impedido o seu agravamento 


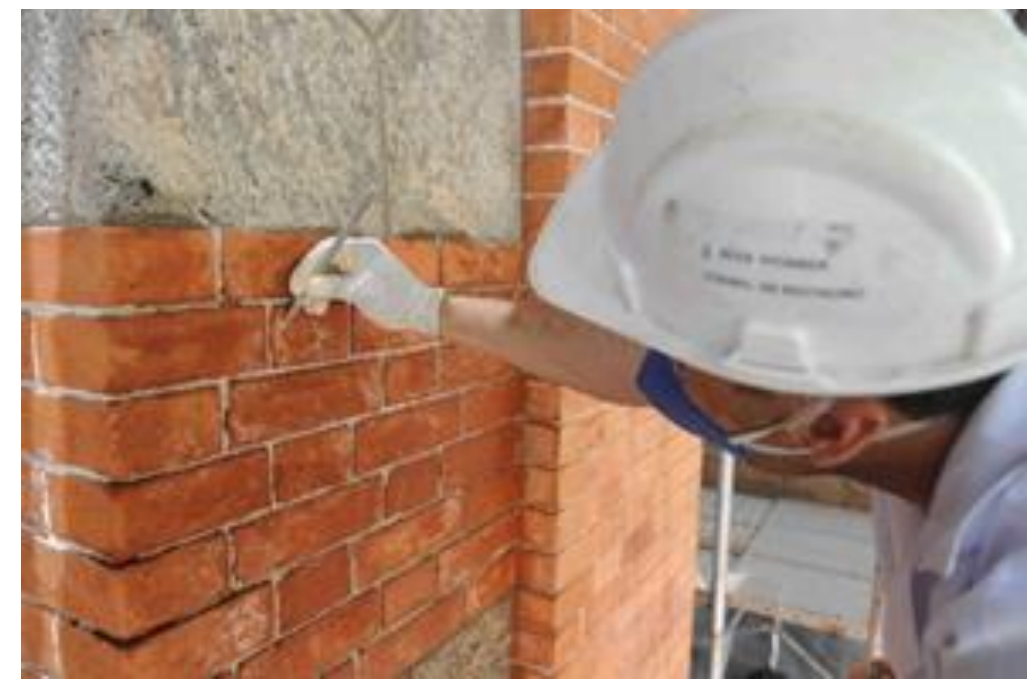

Figura 12 - Restauração dos tijolos aparentes da fachada (2014-2015). Fonte: $\mathrm{DPH} / \mathrm{COC} /$ Fiocruz

O Plano de Requalificação do NAHM surgia naquele momento como uma grande oportunidade de se pensar uma nova ocupação dos espaços históricos de maneira integrada entre as diversas demandas do edifício e os objetivos da exposição. Foi elaborado um documento que buscou identificar os valores associados ao edifício para justificar e estabelecer critérios de intervenções para exposições (DEPARTAMENTO DE PATRIMÔNIO HISTÓRICO, CASA DE OSWALDO CRUZ, 2014).

Nesse âmbito, o projeto para a nova exposição na Cavalariça foi desenvolvido a partir de um conceito que buscava aliar a preservação do edifício enquanto patrimônio cultural ao uso como espaço para atividades de divulgação científica realizadas pelo Museu da Vida. A partir da identificação dos elementos mais relevantes para a preservação do significado cultural do edifício, foram definidas orientações para a elaboração do novo projeto museográfico que, de maneira geral, deveria garantir a leitura destes elementos e a realização das ações relacionadas à 
96 Arquitetura e espaços... Pinheiro, M.; Bevilaqua, D.; Sá, B.; Zouain, S.

conservação preventiva do edifício, desde vistorias até ações corretivas necessárias.

As esquadrias (portas e janelas) deverão permanecer desobstruídas para garantir tanto as ações de conservação preventiva quanto a leitura do bem cultural em sua plenitude.

As instalações de caráter provisório ou permanente deverão ser executadas de forma reversível e harmoniosa com a arquitetura do edifício. Como elemento relevante na configuração do espaço, a volumetria do telhado deverá permanecer livre de interferências de equipamentos ou instalações permanentes ou provisórias.

Os azulejos e pisos que revestem o edifício não poderão ser removidos ou perfurados.

As baias existentes não poderão ser removidas e deverão permanecer desobstruídas.

A solução para garantir acessibilidade ao edifício deverá considerar as limitações inerentes à preservação do bem cultural em questão. A solução de menor impacto para o edifício é a utilização do acesso existente pela porta localizada na fachada oeste. Sendo assim, é recomendável que o projeto museográfico considere este ao definir o percurso da exposição.

Os dispositivos museográficos não poderão exceder a altura das muretas dos corredores laterais no salão das cocheiras.

A iluminação natural da edificação deverá ser priorizada e a iluminação cenográfica deverá ser desenvolvida nos dispositivos museográficos (DEPARTAMENTO DE PATRIMÔNIO HISTÓRICO, CASA DE OSWALDO CRUZ, 2014). 


\section{Projeto expositivo}

O projeto expositivo para a Cavalariça busca marcar dois aspectos principais. Em primeiro lugar, deve-se considerar o papel da edificação como uma das primeiras construídas especialmente para o novo instituto que surgia, atendendo a uma dinâmica científica fundamental para apoiar as ações de saúde no início da primeira república. Seu papel vinha ser o de criação de cavalos para a produção de soros que tinham como objetivo eliminar as principais epidemias que o país sofria naquele momento. O tema proposto para a exposição trata portanto de trabalhar com o público uma visão ampliada de saúde. Da mesma forma que na Cavalariça se usava a microbiologia para a resolução de problemas sociais de saúde pública, a exposição proposta para o edifício também busca apresentar ao grande público uma visão de saúde que vai da microbiologia até a saúde como fenômeno social e global, passando por temas como diversidade microbiana, imunização, visões culturais da saúde, epidemiologia, saúde ambiental e dinâmicas globais de saúde. Nesse sentido é como se a exposição fosse uma espécie de índice para as futuras exposições que serão abrigadas no complexo arquitetônico do NAHM, já que também será a primeira a abrir as portas. Dentro dos eixos temáticos definidos anteriormente, vincula-se principalmente aos eixos de "Ciência e Tecnologia em Saúde" e "Saúde, Ambiente e Sustentabilidade", sendo transpassado também pelo eixo de "Acervos Culturais da Saúde" e "Saúde Pública no Brasil".

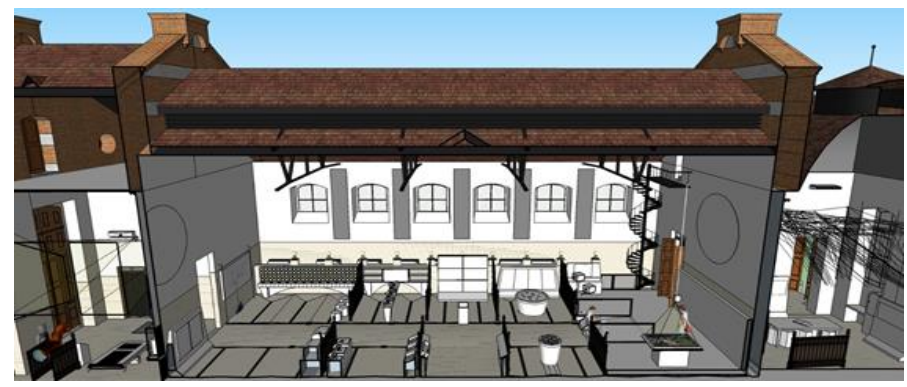


98 Arquitetura e espaços... Pinheiro, M.; Bevilaqua, D.; Sá, B.; Zouain, S.

Figura 13 - Simulação da exposição no interior da Cavalariça. MV/COC.

Do ponto de vista museográfico, como dito anteriormente, busca-se respeitar as linhas arquitetônicas da própria edificação, aproveitando própria estrutura de baias pré-existente para a separação dos módulos expográficos, assim como os grandes volumes do edifício. Para evitar uma visão estruturalista do tema, o público será levado a entrar pela porta central do prédio, diferente das montagens de exposições anteriores, e assim poderá explorar de forma não linear a exposição, podendo ir do micro para o macro ou vice-versa. Dessa forma também, a porta de entrada passa a ser voltada para a Praça Pasteur, praça que unifica a maior parte das edificações prevista no Plano de Requalificação, e que terá uma função agregadora dentro dos espaços museológicos.

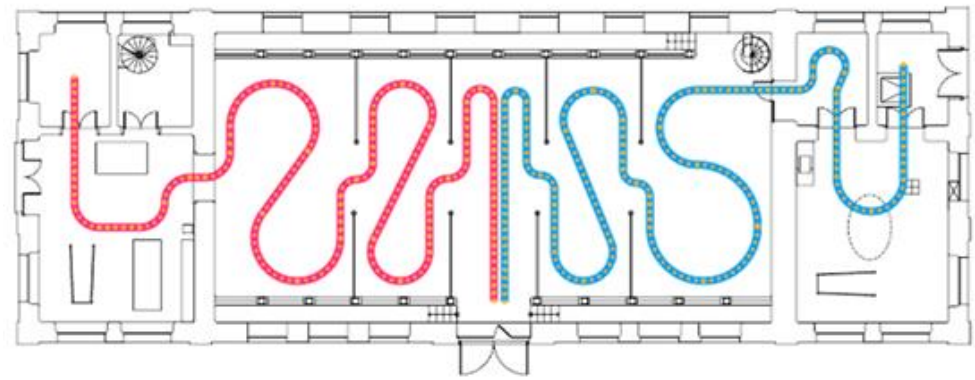

Figura 14 - Percursos da exposição proposta. MV/COC.

A exposição prevê uma multiplicidade de linguagens expográficas, sendo utilizados dioramas, projeções, projeções interativas, módulos interativos (hands-on), conteúdos audiovisuais, oficinas e vitrines expositivas. Dessa forma busca uma flexibilidade de técnicas e linguagens de forma a se adequar na forma mais adequada ao espaço preservado. Os recursos de acessibilidade, limitados pela proteção do patrimônio foram integrados, na medida do possível aos próprios recursos expográficos. 


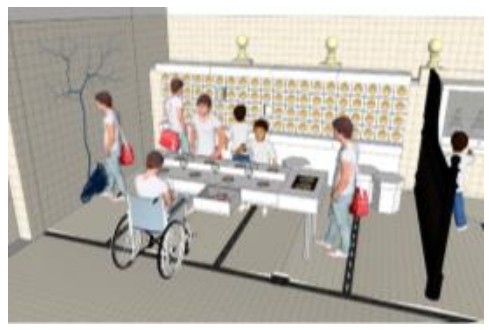

Figura 15- Projeto de módulo expositivo. MV/COC

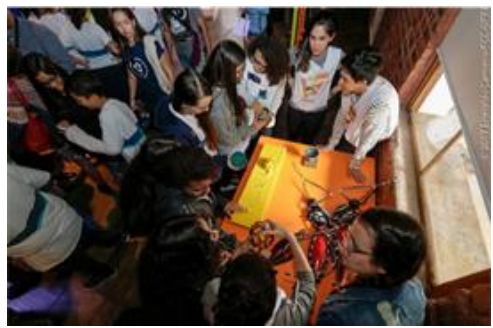

Figura 16- Mediação durante exposição. MV/COC.

\subsection{Pombal}

O Pombal foi construído entre 1904 e 1907 para abrigar um viveiro para animais sadios de pequeno porte, utilizados nas pesquisas desenvolvidas nos primeiros anos do Instituto. Situado na área de entorno imediato do Pavilhão Mourisco, Cavalariça e Pavilhão do Relógio, o conjunto é composto por dois espaços murados, com traçado sinuoso, onde foram dispostos oito módulos cilíndricos divididos em gaiolas para abrigavam estes animais. Os módulos foram dispostos de forma simétrica em relação à torre central que funcionava de abrigo para os pombos-correios utilizados para a comunicação dos pesquisadores do então Instituto Oswaldo Cruz com a Diretoria Geral de Saúde Pública, no centro do Rio de Janeiro. Havia ainda tanques no interior do terreno para a criação de rãs e tartarugas (DIAS, 1918). No livro sobre a formação do Campus Fiocruz Manguinhos, o Pombal é descrito como "um conjunto leve, harmônico e despretensioso, deixando os poucos ornamentos para detalhes decorativos em argamassa, como arremates de telhados e guarda-corpo da escada que imitam troncos de árvores (OLIVEIRA, COSTA e PESSOA, 2003). 


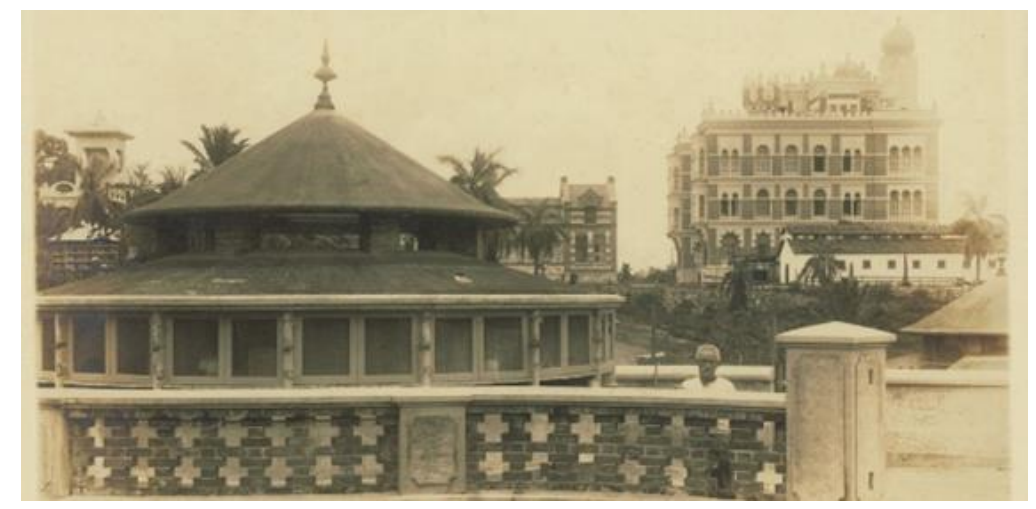

Figura 17 - Um dos módulos de biotério do conjunto do Pombal, com o Pavilhão Mourisco ao fundo. Fonte: Acervo DAD/COC.

Inicialmente, o terreno onde foi construído o conjunto era bastante árido, as árvores foram plantadas alguns anos depois do final da construção. Depois de perder sua função original, ficou abandonado até que, na década de 1980 , foi palco de diversos eventos culturais e celebrações dentro do clima de redemocratização que a Fiocruz vivia. Após a abertura do Museu da Vida, em 1999, foi objeto de um conjunto de projetos de uso que incluíam seu uso para exposições, como local para atividades didáticas e lazer (GRUZMAN, FERREIRA e MAYRINK, 2017). Com o objetivo de tornar o ambiente mais propício para as atividades propostas, uma série de intervenções no espaço foram realizadas, como a vedação dos vãos dos módulos cilíndricos com panos de vidros temperados, a pavimentação dos pátios internos entre outros. No entanto, a melhora nas condições de uso não foi alcançada e um consenso sobre seu uso não foi atingido afastando o uso espontâneo que antes acontecia nestas áreas livres. 


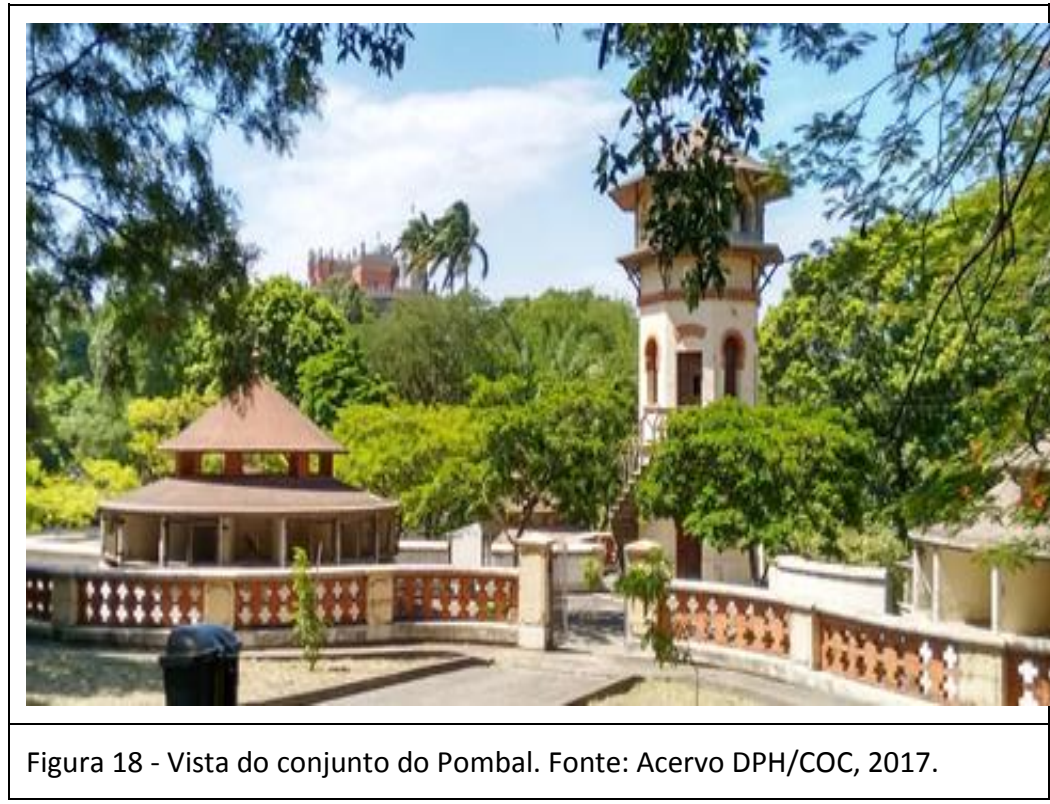

Atualmente, o espaço é pouco utilizado, sobretudo por conta das condições desfavoráveis de conforto ambiental e acessibilidade. O diagnóstico elaborado para orientar o projeto de restauração, identificou danos estruturais relacionados a processos erosivos e direcionamento inadequado das águas pluviais. Diante disto, o conjunto sofre com a presença de fissuras e trincas nas alvenarias e oxidação das ferragens das argamassas armadas, decorrentes da ação das intempéries e da infiltração de água nas bases das muretas e dos módulos. O projeto de restauração proposto pretende sanar esses danos além de remover elementos introduzidos em intervenções anteriores que comprometem a leitura do bem, além de impedir a ventilação adequada.

Para orientar a definição do novo uso para o espaço, o DPH estabeleceu diretrizes gerais para a intervenção, entre elas a definição de um uso compatível com as características do bem, a preservação das visadas internas e externas de forma a resguardar a 
102 Arquitetura e espaços... Pinheiro, M.; Bevilaqua, D.; Sá, B.; Zouain, S. relação do conjunto com o entorno e a adoção de soluções que preservem o caráter singelo e rústico do espaço.

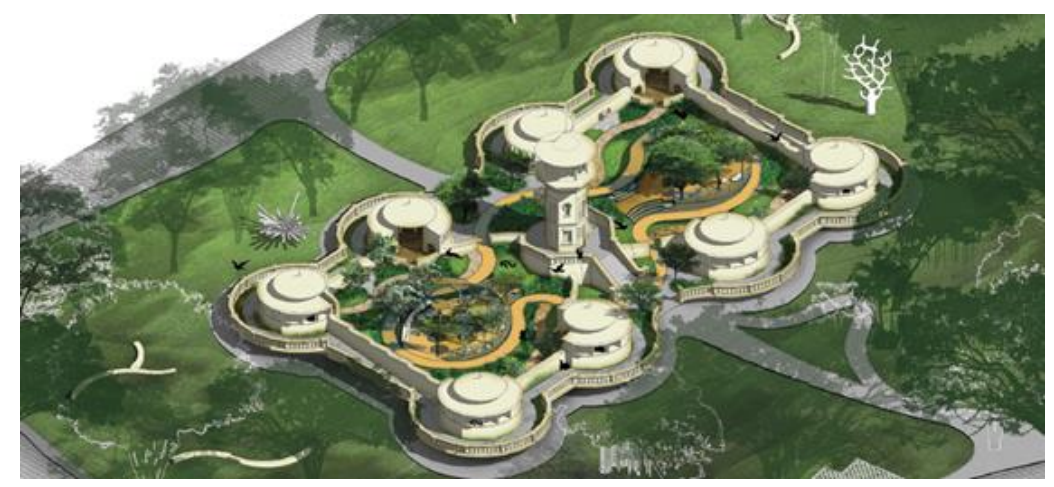

Figura 19 - Projeto para o conjunto do Pombal. DPH/COC.

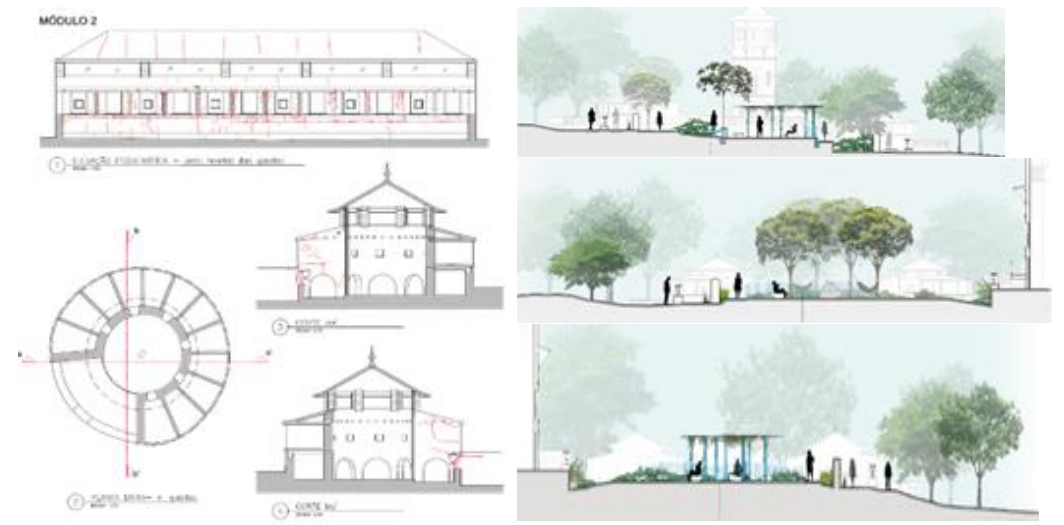

Figura 20- Projeto para o conjunto Figura 21 - Projeto para o conjunto do do Pombal. DPH/COC.

Pombal. DPH/COC.

\section{Projeto expositivo}

Para o projeto de uso do Pombal foram levando em conta principalmente três características de seu uso: sua relação estreita 
com a vida animal dentro do campus e com a temática da experimentação animal dentro da ciência; seu histórico de ser um espaço de encontro e usos espontâneos culturais; e seu uso recente integrado com as trilhas histórico-ecológicos dentro do Campus de Manguinhos - inclusive integrado com o Caminho Oswaldo Cruz (trilha histórica recuperada recentemente, também como parte do Plano de Requalificação do NAHM).

Dessa forma ficou definido como um espaço multitemático, atravessado pelos eixos de "Saúde, Ambiente e Sustentabilidade", "Fiocruz e as Cidades" e "Ciência e Tecnologia em Saúde". Sua proposta de uso leva em conta o potencial do espaço de ser apropriado pelo público como um espaço de lazer e também de eventos ocasionais de cunho cultural. Para a quadra do entorno da edificação estão previstos diferentes módulos interativos (hands-on) de caráter manual e rústico, de apelo ao público infanto-juvenil e de obras de caráter mais artísticos que permitam a exploração de elementos da natureza presentes no local, de forma a apoiar essa relação do espaço com a natureza do local e criar um ponto de apoio às trilhas no interior do campus.
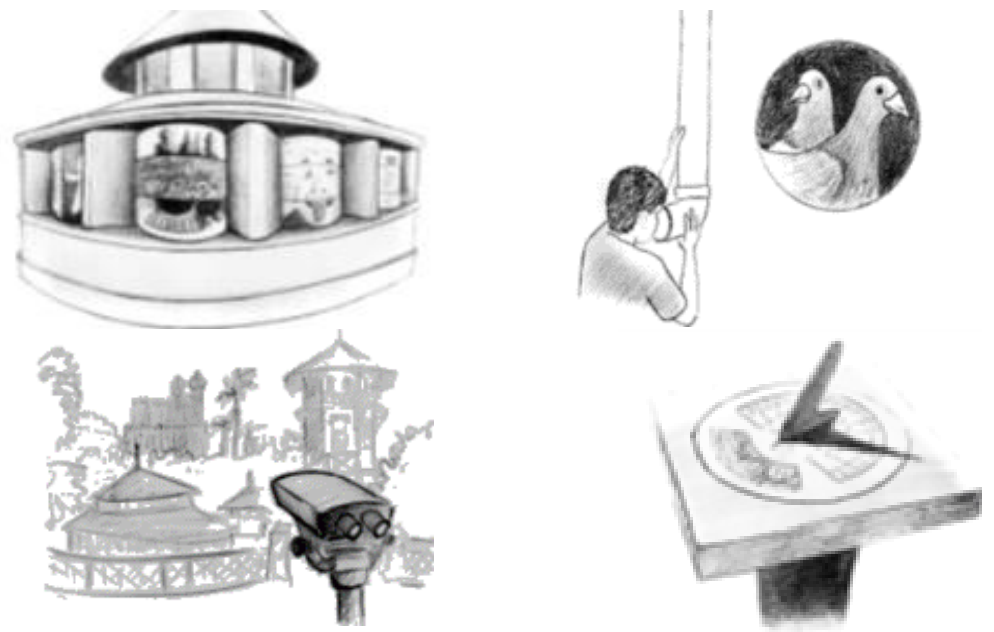

Figura 22 - Projeto expositivo para o Pombal. MV/COC. 
104 Arquitetura e espaços... Pinheiro, M.; Bevilaqua, D.; Sá, B.; Zouain, S.

Para os espaços internos, em particular nos módulos cilíndricos e na torre central, estão previstas intervenções expositivas, também de partido rústico e de interação manual, que dialogue com temas periféricos a edificação: uso do espaço como abrigo para animais de experimentação em laboratórios; história da edificação; uso de pombos correios; e história ambiental do campus. Esse espaço prevê uma exploração mais livre e autônoma do público que também deve contar com amplos espaços de lazer para uso em geral, como mesas, bancos ao ar livre, etc.

\section{Perspectivas}

Considerado o já transcorrido para implementação do Plano de Requalificação, o que se descortina é ainda um longo percurso, se considerado que se trata de um planejamento para minimamente mais dez anos até sua total concretização. Nesse tempo, a expectativa se desdobra em diferentes formas de apreensão e denota persistência, resiliência e capacidade de inovação e de transformação frente aos desafios de uma conjuntura sociopolítica e econômica bastante obscura no contexto nacional, acentuada a partir de 2016, e marcada por recentes retrocessos quanto às questões sociais, à democracia e aos direitos humanos, com impactos diretos à ciência, educação e cultura. Soma-se a isso, uma também instabilidade sociopolítica na região latino-americana e a crescente fragilidade do país às mudanças que ocorrem num hemisfério norte sob tensões. Por outro lado, esse cenário que se avizinha é o mesmo que reafirma a relevância de um projeto dessa natureza para o território, a cidade e a região, pois significa resistência, diálogo e utopia, e reveste-se de valores estruturantes de uma vida cidadã e de sociedades mais livres, justas e solidárias. Mais do que nunca, planejar estrategicamente nesse cenário é fundamental para promover movimentos que busquem construir soluções sustentáveis e alternativas de futuro. 
Os projetos que estão em curso visam a dar sequência à Fase 02 do projeto e que inclui as áreas já disponibilizadas no Pavilhão Mourisco, ou seja, no segundo pavimento as salas Oswaldo Cruz e Carlos Chagas, e grande parte da ala sul do terceiro pavimento, destinada a abrigar uma grande exposição de longa duração centrada no eixo Acervos Culturais da Saúde. Inclui também os projetos referentes à Praça Pasteur, ao Pavilhão do Relógio, à Casa de Chá e à iluminação monumental do NAHM. A isso tudo, por se tratar de um planejamento de longa duração, mantém-se a necessidade de sua constante atualização e de uma estratégica ação de reafirmação do pacto institucional em benefício da implantação desse plano de requalificação.

Dessa forma, o Plano de Requalificação do NAHM se coloca como um grande projeto de intervenção cultural, arquitetônica e urbanística de toda uma área histórica com o compromisso de transformar um território com baixa disponibilidade de equipamentos culturais. Reconfigura o campus de uma instituição federal enquanto um campus-parque e desenha uma visão de futuro para transformação do atual Museu da Vida.

\section{Referências bibliográficas}

BENCHIMOL, Jaime Larry. Manguinhos do sonho à vida: a ciência na Belle Époque. Rio de Janeiro: Fundação Oswaldo Cruz. 1990.

CASA DE OSWALDO CRUZ. INSTITUTO BRASILEIRO DE ADMINISTRAÇÃO MUNICIPAL. Plano de Ocupação da Área de Preservação do Campus Fiocruz Manguinhos: POAP - Documento Final. Rio de Janeiro: [n.p.], 2011.

DEPARTAMENTO DE PATRIMÔNIO HISTÓRICO. Casa de Oswaldo Cruz/Fiocruz. Plano de Requalificação do NAHM. Diretrizes e Critérios de Intervenção nos Bens Culturais. Rio de Janeiro: [n.p.], 2014.

DIAS, Ezequiel. O instituto Oswaldo Cruz, resumo histórico (1899-1918). Rio de Janeiro (s.i), 1918. 
106 Arquitetura e espaços... Pinheiro, M.; Bevilaqua, D.; Sá, B.; Zouain, S.

DEAN, David. Museum Exhibition: theory and practice. New York: Routledge, 2003.

FUNDAÇÃO OSWALDO CRUZ. VI Congresso Interno. Relatório Final. Rio de Janeiro: Fiocruz, 2010.

FUNDAÇÃO OSWALDO CRUZ. Casa de Oswaldo Cruz. Plano de Requalificação do Núcleo Arquitetônico Histórico de Manguinhos. Documento de Referência. Rio de Janeiro: Fiocruz/ COC [n.p.], 2014.

FUNDAÇÃO OSWALDO CRUZ. Casa de Oswaldo Cruz. Política de preservação e gestão de acervos culturais das ciências e da saúde. Rio de Janeiro: Fiocruz/COC, 2013. Disponível em: http://www.coc.fiocruz.br/images/PDF/politica_preservacao_gesta o_acervos_coc.pdf

FUNDAÇÃO OSWALDO CRUZ. Casa de Oswaldo Cruz. Plano Quadrienal COC 2015-2018. Rio de Janeiro: Fiocruz / Casa de Oswaldo Cruz, 2015

GABRIEL, Carla Gruzman; TEIXEIRA, Luiz Antonio. Espaço biodescoberta: uma exposição interativa em biologia. Hist. cienc. saude-Manguinhos, Rio de Janeiro, v. 6, n. 2, p. 377-393, Oct. 1999

GRUZMAN, Carla; FERREIRA, José Ribamar; MAYRINK, Marta Fabíola. Projects. In: Diego Vaz Bevilaqua; Marina Ramalho; Rita Alcantara; Tereza Costa. (Org.). Museum of Life: Science and Art in Manguinhos. Rio de Janeiro: Fiocruz / Casa de Oswaldo Cruz, 2017, p. $12-25$.

MARANDINO, Martha. The expositive discourse as pedagogical discourse: studying recontextualization in the production of a science museum exhibition. Cultural Studies of Science Education, v. 11, n. 2, p. 481-514, 2016.

OLIVEIRA, Benedito T. (Coord.); COSTA, Renato G. R.; PESSOA, Alexandre J. S. Um Lugar para a Ciência: a formação do campus de Manguinhos. Rio de Janeiro: Editora FIOCRUZ, 2003.

PINHEIRO, Marcos José de Araújo; MARQUES, Ana Maria Osório de Barros Barbero; COELHO, Carla Maria Teixeira. Núcleo Arquitetônico Histórico de Manguinhos (R. J. - Brasil): Proposta de Requalificação para um Patrimônio Cultural da Saúde. In: II Congresso Internacional sobre Património Industrial Património, 
Museus e Turismo Industrial: Uma Oportunidade para o século XXI, 2017, Porto, Portugal. Porto: CITAR / Universidade Católica do Porto/ Associação Portuguesa para o Património Industrial (APPI), 2017. v. 1. p. 254-264

SÁ, Bruno Teixeira de.; MARTIRE, Giovanna. Os desafios da restauração e conservação da Cavalariça do Núcleo Arquitetônico Histórico de Manguinhos, Rio de Janeiro, Brasil. In: Rehabend 2016 Euro-American Congress, 2016, Burgos. Rehabend 2016 - EuroAmerican Congress. Burgos: Universidad de Burgos, 2016. v. 1. p. 2273-2280.

SOARES, Pedro Paulo; NOGUEIRA, Inês. Background. In: Diego Vaz Bevilaqua; Marina Ramalho; Rita Alcantara; Tereza Costa. (Org.). Museum of Life: Science and Art in Manguinhos. Rio de Janeiro: Fiocruz / Casa de Oswaldo Cruz, 2017, p. 12-25. 
